\title{
Yes, I can: a representação das pessoas com deficiência no videoclipe "We're the Superhumans" do Channel 4
}

\author{
Amanda Paola Velasco \\ Antonio Luis Fermino² \\ Bianca Natália Poffo 3 \\ Silvan Menezes dos Santos ${ }^{4}$
}

\section{RESUMO}

Este trabalho se propôs a responder a seguinte questão: de que maneira as pessoas com deficiência são retratadas no videoclipe "We're the Superhumans" produzido pelo canal de televisão inglês, Channel 4, e divulgado pelo IPC para promover os Jogos Paralímpicos Rio/2016? Como base metodológica, utilizamos a análise do discurso e elencamos duas categorias: Espetacularização da deficiência (supercrip) e Representação das pessoas com deficiência. Identificamos que as pessoas com deficiência foram apresentadas sob a ótica das capacidades e habilidades socioesportivas. A peça publicitária se restringiu em veicular conteúdos que promovem a surpresa e o encantamento do público, omitindo, por vezes, problemáticas desse universo, assim como a questão da acessibilidade. Constatamos também a mobilização de três elementos para a representação das pessoas com deficiência: 1 - Discurso nacionalista; 2 - A mediação informativa das modalidades paralímpicas; e 3 - A projeção de futuro a partir da imagem da criança e de novas modalidades esportivas.

Palavras-chave: Atletas com deficiência. Supercrip. Representante. Estigma.

1 Mestrado em andamento na área de Educação Fìsica, pela Universidade Federal do Paraná (UFPR). Curitiba/ Paraná, Brasil. E-mail: amandavelasco.18@gmail.com

2 Doutorado em andamento na área de Educação Fìsica, pela Universidade Federal do Paraná (UFPR). Curitiba/ Paraná, Brasil. E-mail: antonioluisf@gmail.com

3 Doutorado em andamento na área de Educação Fìsica, pela Universidade Federal do Paraná (UFPR). Curitiba/ Paraná, Brasil. E-mail: bia.poffo@hotmail.com

4 Doutorado em andamento na área de Educação Fìsica, pela Universidade Federal do Paraná (UFPR). Curitiba/ Paraná, Brasil. E-mail: bammenezes90@gmail.com 
Yes, I can: the representation of persons with disabilities in the video "We're the Superhumans" of the Channel 4

\begin{abstract}
This paper sets out to answer the following question: how are people with disabilities portrayed in the video "We're the Superhumans" produced by the english channel, Channel 4, and released by the IPC to promote the Rio 2016 Paralympics Games? As a methodological basis, we used discourse analysis and listed two categories: Disability Spectacularization (supercrip) and Representation of people with disabilities. We identified that people with disabilities were presented from the perspective of social and sports skills and abilities. The piece of advertising was restricted to convey contents that promote the surprise and the enchantment of the public, omitting sometimes problematic of this universe, as well as the question of accessibility. We also note the mobilization of three elements for the representation of people with disabilities: 1 - Nationalist discourse; 2 - The information mediation of the Paralympic modalities; And 3 - The projection of the future from the image of the child and new sports modalities.
\end{abstract}

Keywords: Athletes with disabilities. Supercrip. Representative. Stigma.

Yes, I can: la representación de las personas con discapacidad en el video "We' re the Superhumans" del Channel 4

\title{
RESUMEN
}

Este artículo pretende contestar a la siguiente pregunta: ¿Cómo se retratan las personas con discapacidad en el video "We 're the Superhumans" producido por el canal inglés, Channel 4, y publicado por el IPC para promover los Juegos Paralímpicos de Río / 2016? Como base metodológica, se utilizó el análisis del discurso y indicamos dos categorías: espectacularización de la discapacidad (supercrip); y la representación de las personas con discapacidad. Hemos identificado que las personas con discapacidad se presentaron desde la perspectiva de habilidades y capacidades sociales y deportivas. La publicidad se limitaba a transmitir contenidos que promovieran la sorpresa y el encantamiento del público, omitiendo a veces problemática de este universo, así como la cuestión de la accesibilidad. También observamos la movilización de tres elementos para la representación de las personas con discapacidad: 1 - Discurso nacionalista; 2 - La mediación de la información de las modalidades paraolímpicas; y 3 - La proyección del futuro desde la imagen del niños y las nuevas modalidades deportivas.

Palabras clave: Los atletas con discapacidad. Supercrip. Representante. Estigma. 


\section{INTRODUÇÃO}

"Yes, I Can!" (Sim, eu posso!), assim inicia a letra do videoclipe, "We're the Superhumans" ${ }^{5}$ (Nós somos os Super-humanos), produzido e divulgado pelo Channel 4 e pelo IPC (International Paralympic Committee). A produção teve como objetivo promover os Jogos Paralímpicos Rio/2016 e os atletas que participaram do megaevento no período de 07 a 18 de setembro de 2016. Em uma composição entre música e imagens, o videoclipe nos possibilita diferentes reflexões sobre o modo com que as pessoas com deficiência são retratadas na narrativa midiática. Alguns autores já refletiram, a partir de diferentes categorias, que em muitos casos os atletas com deficiência são representados por meio da criação de heróis ou o que podemos chamar de supercrips (GONÇALVEZ; ALBINO; VAZ, 2009; HARDIN; HARDIN, 2004; SILVA; HOWE, 2012); ou através da vitimização, dando ênfase na tragédia que os levou à deficiência em detrimento do feito esportivo (HILGEMBERG, 2014); ou também pela trivialização e infantilização dos sujeitos, ao serem apresentados por uma outra ótica que não a esportiva (DE LÉSÉLEU; PAPPOUS; MARCELLINI, 2009; DE LÉSÉLEUC; PAPPOUS; MARCELLINI, 2010; PAPPOUS; MARCELLINI; DE LÉSÉLEUC, 2011; PAPPOUS et al, 2007).

Cotidianamente, somos influenciados por discursos variados que criam determinados personagens para diferentes campos de atuação. Seja no esporte, na educação, na política, na economia, na cultura e/ou na comunicação social, encontramos personagens que podemos denominar como representantes de um grupo social ao qual ele - o representante - pertence (GOFFMAN, 2015). No caso das pessoas com deficiência não seria diferente. Em muitas situações atletas se consolidam como modelo para esse grupo de pessoas por vezes ainda estigmatizadas e marginalizadas na sociedade. Os atletas se tornam exemplos de um grupo de pessoas estigmatizadas pelas suas "deformidades físicas" como denominou Goffman (2015) na década de 1960, isto porque "[...] apresentam o caso em nome dos estigmatizados e, quando elas próprias são 'nativas' do grupo, fornecem um modelo vivido de uma realização plenamente normal; são heróis da adaptação, sujeitos a recompensas públicas [...]" (GOFFMAN, 2015, p. 34).

Segundo Purdue e Howe (2012), muitas pessoas ainda possuem a concepção de que a deficiência é uma doença e que as pessoas com deficiência lutam contra suas próprias limitações. Para reverter esse olhar, órgãos reguladores do esporte paralímpico (IPC, $\mathrm{CPB}^{6}$ ) em todo o mundo vem desenvolvendo campanhas para que a sociedade mude a perspectiva e consiga visualizar as capacidades das pessoas com deficiência, como é o caso do vídeo do Channel 4. Neste sentido, este trabalho se propõe a responder a seguinte questão: de que maneira as pessoas com deficiência são retratadas no videoclipe We're The Superhumans produzido pelo canal de televisão inglês, Channel 4, e divulgado pelo IPC para promover os Jogos Paralímpicos Rio/2016?

5 Vídeo produzido pelo Channel 4 e disponível neste link: https://www.youtube.com/watch?v=locLkk3aYlk

6 Comitê Paralímpico Brasileiro. Site oficial: http://www.cpb.org.br/ 
Ressaltamos a importância desta produção audiovisual aqui analisada diante do alcance que ela teve, com mais de 7,5 milhões de visualizações na sua publicação oficial no Youtube ${ }^{7}$. Entendemos também que as mídias de maior alcance social, tais como a televisiva e a virtual, possuem um papel fundamental na "[...] construção do imaginário sobre a pessoa com deficiência e suas potencialidades de atuação plena" (MARQUES, 2016, p. 92), e por isso é imprescindível refletir sobre a maneira como ela - a mídia - costuma representar as pessoas com deficiência, os atletas e o esporte paralímpico.

\section{METODOLOGIA}

Para o desenvolvimento desta pesquisa, optamos por uma abordagem qualitativa dos dados. Como aporte metodológico ${ }^{8}$, utilizamos a análise do discurso, a qual não se tratou apenas de análise da língua ou da sua forma gramatical, mas de compreendermos os sentidos que estão postos na mensagem (ORLANDI, 1999). Ou seja, não olhamos apenas para o que estava visível aos olhos. Procuramos entender o que estava intrínseco a partir do contexto de produção do material audiovisual (LIMA; CARVALHO, 2009).

Entendemos que os discursos não são neutros e que pertencem a determinados contextos sociais que Ihes garantem uma demanda de produção, divulgação e recepção. Acreditamos "[...] que o uso e a omissão de determinadas expressões e argumentos não é inócua, mas apresenta uma intencionalidade mais ou menos implícita, sendo, por meio dessas escolhas, reprodutora e produtora de 'verdades'" (GONÇALVES; ALBINO; VAZ, 2009 , p. 150). Portanto, ao realizarmos este trabalho, nos atentamos aos diferentes enquadramentos que as pessoas com deficiência foram postas no videoclipe estudado.

Conforme supracitado, já foram identificadas diferentes possibilidades de se interpretar discursos relacionados às pessoas e atletas com deficiência, dentre eles encontram-se as categorias da vitimização, da infantilização, da trivialização e do supercrip. Estas são categorias que indicam estigmas que normalmente identificam e personificam os atletas com deficiência no discurso midiático-esportivo. Para este trabalho, diferentemente, elencamos duas outras categorias que nos auxiliaram na compreensão de contexto do discurso midiático-esportivo veiculado sobre as pessoas e atletas com deficiência: a primeira foi a Espetacularização da Deficiência, como apontado por Gonçalves, Albino e Vaz (2009). Para estes autores, no contexto do esporte paralímpico a deficiência pode ser transformada em um espetáculo, seja pelos enquadramentos, pela trilha sonora, pelas cores e efeitos especiais acrescentados à midiatização da referida manifestação esportiva ou também pela forma como esses diferentes corpos são apresentados e narrados no contexto midiático-esportivo. Os autores ainda afirmam que o esporte adaptado é o lugar onde o 'anormal',

7 Dado atualizado em fevereiro de 2017.

8 Gostaríamos de agradecer ao Prof. Dr. André Mendes Capraro pelas reflexões durante a disciplina de Esporte, Teoria, Historiografias e Fontes no Programa de Pós-Graduação em Educação Física - UFPR em 2016/1, a partir da qual resultou este trabalho. 
aquilo que foge dos padrões de corpo impostos pela sociedade é exibido e a deficiência se torna um espetáculo para as pessoas sem deficiência apreciarem e se inspirarem. Neste campo de análise questionamos como e quais elementos compuseram o espetáculo sobre as pessoas com deficiência.

A segunda categoria foi a Representação das pessoas com deficiência, que de acordo com Goffman (2015), no caso de grupos sociais que são estigmatizados, normalmente encontram-se representantes destes grupos perante a sociedade. Estes representantes "são pessoas com estigmas que têm, de início, um pouco mais de oportunidade de se expressar, são um pouco mais conhecidas ou mais relacionadas do que os seus companheiros de sofrimento [...]" (GOFFMAN, 2015, p. 35). Seu reconhecimento se dá pela superação das dificuldades ao longo da vida e assim ele se torna um exemplo a ser seguido. Para essa análise, investigamos de que maneira atletas e pessoas com deficiência foram representados no videoclipe.

\section{Contexto de produção do videoclipe}

Nosso objeto de pesquisa - o vídeo We're the Superhumans - foi produzido pelo canal Channel $4^{9}$ - uma emissora aberta do Reino Unido, fundada em 1982 - em parceria com o Comitê Paralímpico Internacional (IPC). Convém esclarecer que, como definido pelo parlamento Inglês, o Channel 4 tem a missão de prestar serviço público oferecendo inovação, distinção e representação de visões alternativas e vozes minoritárias. Ao adquirir os direitos de transmissão dos Jogos Paralímpicos de Londres 2012, esse canal se comprometeu a realizar uma ampla cobertura do evento e explicar o esporte paralímpico de uma forma inovadora, visando torná-lo mais atraente para o público.

Como uma estratégia para divulgar os atletas paralímpicos como atletas de elite para a sociedade, o Channel 4 criou uma campanha com vídeos de 90 segundos de duração, chamada 'Meet the Superhumans'10 (Conheça os Super-humanos). A campanha apresentou uma série de atletas paralímpicos treinando sob uma proposta que descreve a intensidade de uma competição de elite, permeada por uma trilha sonora empolgante. O objetivo seria empoderar os atletas paralímpicos, ao invés de mostrá-los como pessoas que necessitam de piedade ${ }^{11}$. Esta abordagem foi considerada uma quebra de paradigma na forma de veiculação da imagem de pessoas com deficiência.

O resultado dessa campanha foi a criação de uma expectativa pelos Jogos Paralímpicos por parte dos ingleses e, em consequência disso, o canal teve a maior audiência em dez anos durante a transmissão da cerimônia de abertura dos Jogos Paralímpicos de Londres

9 Link: http://www.channel4.com/. “Desde sua fundação em 1982, a Channel 4 tem o objetivo de ser um canal inovador, experimental e educacional, satisfazendo os gostos e interesses não atendidos pelas outras emissoras e, particularmente, pelas redes de TV comerciais" (MEDRADO, 2015, p.46).

10 Por exemplo, um dos vídeos está disponível em: https://goo.gl/FfjcuW

11 Normalmente este tipo de narrativa está vinculada a uma trilha sonora com instrumentos clássicos isolados (como piano e violão) que dão um tom sombrio e triste ao conteúdo. 
em 2012. Aparentemente a campanha 'Meet the Superhumans' e a cobertura dos Jogos Paralímpicos Londres 2012 tiveram impactos sociais sobre o público inglês, despertando a consciência e a compreensão da deficiência no esporte.

Após a repercussão positiva da campanha 'Meet the Superhumans', o canal Channel 4, em parceria com o IPC, criou uma nova campanha denominada 'We're the Superhumans'. A campanha teve a finalidade de divulgar os Jogos Paralímpicos do Rio 2016, além de promover o empoderamento das pessoas com deficiência, disseminando uma imagem de super-humanos, capazes de realizar feitos em todas as esferas da sociedade.

O empoderamento de atletas paralímpicos é um dos objetivos principais da existência do IPC (INTERNACIONAL PARALYMPIC COMMITTE, 2016). Foi com esta intenção de mostrar para o mundo como as pessoas com deficiência são capazes de realizar diferentes ações que o mesmo idealizou o vídeo em questão.

Whe're The Superhumans tem duração de 3 minutos e inicia com uma banda de músicos com variados tipos de deficiência física, tocando a música 'Yes, I can'. A composição escrita da música ${ }^{12}$ transmite a mensagem de que as pessoas com deficiência são capazes de realizar todas as ações que desejam. O vídeo se desenrola mostrando alguns atletas com deficiências diversificadas competindo no âmbito do alto rendimento e desenvolvendo atividades cotidianas, como por exemplo, cuidar dos filhos e trabalhar.

O vídeo mostra pessoas com deficiência como indivíduos independentes, habilidosos e capazes de levar uma vida com menos limitações. Ou seja, ele não focaliza na deficiência das pessoas e sim no que elas podem realizar. Isso pode ser constatado no making off do vídeo ${ }^{13}$, o qual tem uma entrevista com o baterista Alvin Law, que nasceu sem as mãos, e ele chama atenção para o fato de que o objetivo do vídeo não é tratar da deficiência, mas sim sobre talentos 'loucos' ${ }^{14}$ e sobre mostrar as capacidades das pessoas com deficiência. Um outro entrevistado, Tony Dee, deficiente físico e cantor da música do vídeo, relata que o ponto central do vídeo é dizer para ele, como representante das pessoas com deficiência, que é possível fazer mais do que ele jamais sonhou.

Na sequência apresentaremos os percursos interpretativos que seguimos para caracterizar a narrativa midiática que o videoclipe promoveu em relação aos Jogos Paralímpicos Rio/2016, aos atletas e às pessoas com deficiência, compreendendo que podem existir outras trajetórias de leitura e interpretação do conteúdo analisado neste trabalho.

12 Música: We're The Superhumans/Yes, I can, suddenly/Yes, I can/Gee, I'm afraid to go on has turned into/Yes, I can/Take a look, what do you see?/133 Ibs of confidence, me/Got the feeling I can do anything/Yes, I can/ Something that sings in my blood is telling me/Yes, I can/l was just born today/l can go all the way/Yes I can/ (solos de piano, sapateado, guitarras, baterias) Silêncio (Shh - futebol de 5)/Yes, I can/Yes, I can (Língua de Sinais)/Hey, Yes, I can/No. You Can't/Yes, I can/Are you ready?/I cam climb Everest/Yes, I can/l can fight here all night and never rest/Yes, I can/I was just born today/l can go all the way/Yes, I can/Whe're the superhumans.

13 Link: https://www.youtube.com/watch?v=AZ_K22WV7a0

14 Os talentos loucos que o baterista cita no vídeo consistem em realizar determinadas atividades de maneira diferente do que estamos acostumados a observar e fazer, como por exemplo: tocar bateria, guitarra, pilotar um avião, dirigir um carro e escovar os dentes apenas com os pés, entre outras ações nas quais as deficiências parecem não interferir. 
No primeiro momento apresentamos os elementos que compõem a espetacularização da deficiência e em seguida elencamos os aspectos que conformam o grupo da representação das pessoas com deficiência.

\section{Espetacularização da Deficiência (Supercrip)}

Uma das problemáticas da espetacularização da deficiência está na construção estética do discurso, uma vez que para emocionar o público, as narrativas normalmente vêm acompanhadas de histórias trágicas. Essas histórias acabam se configurando em uma narrativa de superação e exemplo para as pessoas com ou sem nenhuma deficiência, e isso acaba se conformando em um elemento representativo da imagem do atleta como aquele que sofre, passa por inúmeras adversidades na vida, mas que se supera, persiste e vence no esporte e na vida (GONÇALVES, ALBINO E VAZ, 2009). Esse discurso de superação que transforma o atleta com deficiência em um astro ou um herói é denominado pela literatura como supercrip (GONÇALVES; ALBINO; VAZ, 2009; HARDIN; HARDIN, 2004; SILVA; HOWE, 2012; HILGEMBERG, 2014).

O vídeo 'Whe're the Superhumans' apresenta uma quebra de paradigma na forma de representação do atleta, pois transforma as pessoas com deficiências em super-heróis e super-humanos por realizarem não só feitos esportivos, mas também atividades cotidianas ${ }^{15}$. O diferencial dessa produção audiovisual é que ela não contém um apelo emocional como o do modelo supercrip descrito anteriormente. O vídeo se preocupa em mostrar pessoas comuns em seu dia-a-dia, independente da história de vida delas, sem apresentar os elementos trágicos das situações que os levaram à deficiência.

No transcorrer do videoclipe, as imagens apresentam pessoas com diferentes tipos e graus de deficiência, em diversificadas situações do cotidiano - dançando, tocando instrumentos musicais, cantando e praticando esporte -, além de mostrar variadas formas de adaptação que essas pessoas buscam para realizar tais ações. Ao não apelar para elementos trágicos e dramáticos das histórias dos atletas na construção do vídeo, o Channel 4 e o IPC acabam reproduzindo uma narrativa (a do supercrip) que pode ajudar no reconhecimento social dos atletas paralímpicos e no respeito à diversidade das pessoas com deficiência por parte da sociedade (SILVA; HOWE, 2012; HILGEMBERG, 2014).

O videoclipe começa com a orquestra, composta por pessoas com diferentes deficiências, tocando instrumentos diversos e de maneiras variadas. Depois, o vídeo mostra atletas com diferentes graus e tipos de deficiências, em diferentes modalidades como ciclismo, natação, boxe e atletismo, como por exemplo, atletas amputados, com deficiência intelectual, com nanismo, entre outros. No decorrer do clipe, também são apresentadas pessoas com deficiência trabalhando em um escritório e utilizando os pés para escrever, uma criança comendo com os pés e uma mãe cuidando do bebê também com os pés, assim como um amputado dos membros superiores pilotando um carro com os pés e fazendo 
manobras radicais. Todos esses elementos apresentados no vídeo mostram que o processo de espetacularização da deficiência pode ser realizado respeitando a diversidade interna do grupo social e valorizando as capacidades e habilidades dos mesmos sem focar nas suas deficiências, mas também sem ocultá-las. Essa é uma forma de respeitar a identidade das pessoas com deficiência, pois "a deficiência é parte da identidade social dos atletas paralímpicos [como também, de não atletas], e ignorando a deficiência se ignora parte de quem eles são" (BUYSSE; BORCHERDING, 2010, p. 318). Assim também acontece nos fragmentos do videoclipe em que bailarinos dos dois sexos aparecem dançando com próteses que se movimentam de forma independente (próteses que são mostradas soltas e dançando no ritmo da música). Isso também pressupõe uma narrativa de respeito à diversidade de gênero no contexto das pessoas com deficiência.

O videoclipe também mostra pessoas com deficiência em diferentes ambientes sociais: um escritório, uma pista de dança, uma pista de atletismo, um supermercado e uma quadra de esportes. A composição dessas imagens pode gerar a percepção de que esse grupo de pessoas pode estar presente nas nossas ambiências do cotidiano e acessá-las sem nenhum problema. Apesar de ser uma narrativa que pode estimular o reconhecimento social das pessoas com deficiência, conforme supracitado, e mesmo compreendendo que é uma peça publicitária com interesses e objetivos específicos na promoção dos Jogos Paralímpicos 2016, a forma como a narrativa é apresentada no videoclipe acaba omitindo os problemas de acessibilidade que são enfrentados cotidianamente por essas pessoas na maioria das cidades do mundo. Esse fator é potencializado no momento do videoclipe, apresentado na figura 1 logo a seguir, que demonstra como as deficiências compreendidas sob a lógica do espetáculo e do supercrip ignoram o obstáculo que é se deparar com uma escadaria para subir ou descer em qualquer ambiente. Neste caso, o personagem desce as escadas com a cadeira de rodas sem nenhuma dificuldade, o que é praticamente impensável em nosso cotidiano. Como afirma Debord (1997), é o espetáculo criando uma segunda realidade.

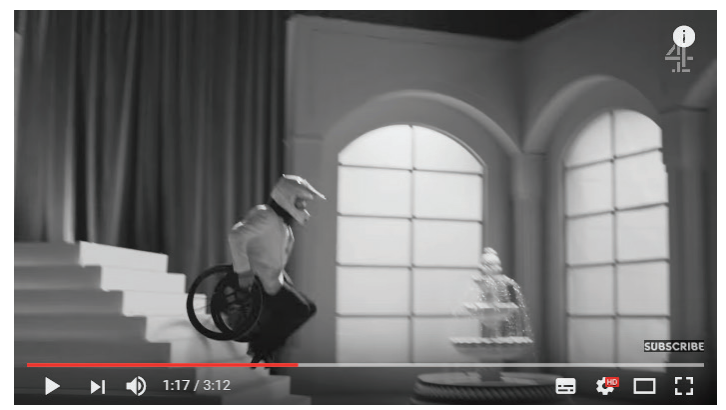

Figura 1

Fonte: Videoclipe "We're the Superhumans"

Sem desconsiderarmos que esta é uma peça publicitária voltada especificamente à promoção dos Jogos Paralímpicos junto ao público, entendemos que o reconhecimento 
social que pode vir a se efetivar por intermédio do objeto de estudo, pode ser considerado restrito ao consumo dos Jogos Paralímpicos como mais um produto da cultura esportiva massificada. A narrativa audiovisual apresenta os atletas, as capacidades esportivas e as habilidades cotidianas deles superestimando-as, revelando que o caráter surpreendente destes feitos está vinculado não somente, mas também ao fato de normalmente se ter baixas expectativas sociais com relação às habilidades e capacidades dessas pessoas. Silva e Howe (2012) ressaltam que este é um dos problemas da narrativa do supercrip, quando ela apenas idolatra os feitos esportivos e não ajuda a esclarecer e a chamar atenção da sociedade para o modo como se estigmatiza e se olha para este grupo de pessoas. Ou seja, uma narrativa que emociona, encanta e promove a surpresa dos espectadores por nunca se ter imaginado que algum indivíduo com deficiência poderia alcançar o sucesso em algum setor da sociedade, mas não ajuda a perceber que caso depositássemos confiança e credibilidade nas habilidades e capacidades das pessoas com deficiência, um feito esportivo poderia não ser tratado como algo extraordinário ou espetacular.

O que podemos visualizar no videoclipe, conforme os frames subsequentes apresentados nas figuras 2 e 3, é um recrutador de trabalhadores afirmando ao usuário de cadeira de rodas de que "não, ele não pode", e na sequência o mesmo personagem com deficiência demonstrando força, jogando rugby em cadeira de rodas e afirmando "sim, eu posso". Esse discurso supera a problemática apontada por Silva e Howe (2012) relacionada com a omissão do esclarecimento das barreiras e preconceitos sociais, e materializa aquilo que seria a mudança de paradigma do modelo médico para o modelo social de se compreender e olhar a deficiência. Nessa mudança, como afirma Coakley (2009), se desliza o modo de compreender a deficiência e a pessoa com deficiência de uma perspectiva individualizante, personificada, em que o problema está unicamente na pessoa, para uma perspectiva de problema coletivo e social, na qual a questão é percebida pelo modo como a sociedade se organiza ou deixa de se organizar.

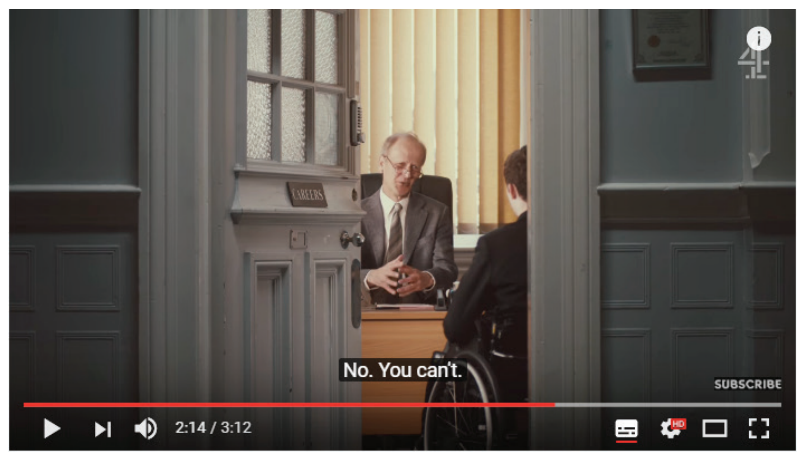

Figura 2

Fonte: Videoclipe "We're the Superhumans" 


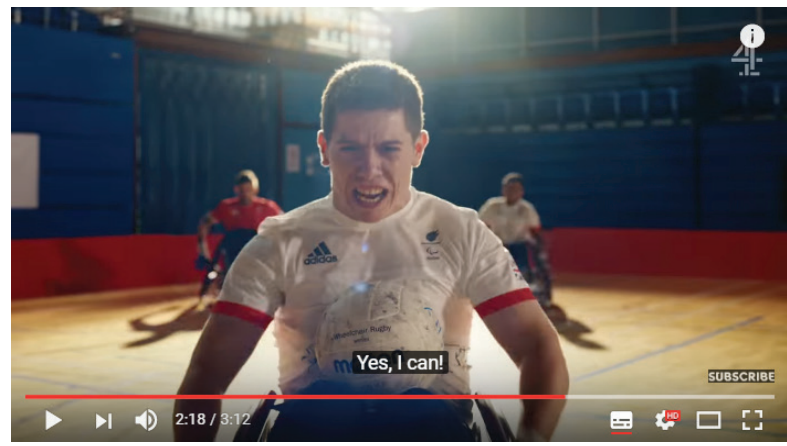

Figura 3

Fonte: Videoclipe "We 're the Superhumans"

Esta passagem do videoclipe exemplifica um dos problemas e dificuldades sociais e estruturais que eles enfrentam no cotidiano mesmo sendo capazes de tantas ações. Esta característica do vídeo está associada à compreensão de Tynedal e Wolbring (2013), de que a omissão de dificuldades e preconceitos em relação à pessoas com deficiências em narrativas midiáticas não contribui para a consolidação do esporte paralímpico na sociedade. Segundo os autores, esse tipo de narrativa não ajuda a reduzir a marginalização e segregação desse grupo na sociedade, pois não revela questões como os problemas de acessibilidade, a falta de apoio social e os altos custos dos produtos de tecnologia terapêutica para as pessoas com deficiência.

Em síntese, compreendemos que a narrativa do vídeo analisado espetaculariza o esporte paralímpico sem dramatizá-lo, pois, abdica de contar as histórias de vida e as possíveis tragédias pelos quais os atletas possam ter passado, para enfatizar as habilidades e capacidades socioesportivas deles, respeitando também a diversidade social e corporal existente entre as pessoas com deficiência. Em paralelo a isso, embora tenha apresentado uma situação representativa do preconceito e da descrença social com relação às pessoas com deficiência, a peça publicitária veicula predominantemente conteúdos que promovem a surpresa e o encantamento do público junto aos protagonistas do espetáculo paralímpico, sem revelar questões problemáticas centrais existentes e fundamentais do contexto das pessoas com deficiência, como os obstáculos de acessibilidade enfrentados pelas mesmas no cotidiano das cidades.

\section{Representação das pessoas com deficiência}

Diante dos efeitos especiais e das realizações quase que impossíveis de serem feitas, o discurso midiático proporciona emoção, sensibilidade, atração, reconhecimento de pertencer a um grupo, ou de se sentir representado por este coletivo ou por alguém. Tais sentimentos são reflexos de um conteúdo minuciosamente pensado a partir de uma 
estética que nos é sensível. Isso, de certa maneira, nos instiga a refletir sobre a relação com o outro e as possibilidades de ver o mundo a partir do outro.

O discurso midiático pode promover um olhar estigmatizante ao representar determinados sujeitos sob uma identidade social virtual, que conforme afirma Goffman (2015), são as expectativas normativas e as exigências que carregamos a partir de nossas pré-concepções e que acabamos atribuindo ao outro. Essa identidade virtual seria, então, um olhar estereotipado, construído a partir do senso comum e que realça determinadas características de uma pessoa ou grupo social que não são necessariamente reais. "No estudo sociológico das pessoas estigmatizadas, o interesse está geralmente voltado para o tipo de vida coletiva, quando esta existe, que levam aqueles que pertencem a uma categoria particular" (GOFFMAN, 2015, p. 30). Neste aspecto, ressaltamos a importância de compreendermos a representação de coletividade das pessoas com deficiência que estão expressas na produção do videoclipe analisado.

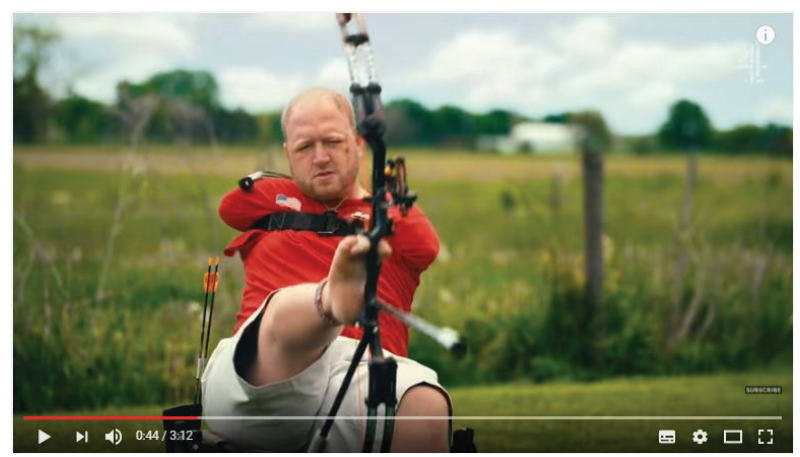

Figura 4

Fonte: Videoclipe "We're the Superhumans"

O representante de um grupo, nesse caso o das pessoas com deficiência, pode influenciar outros grupos estigmatizados, pois "a eleição de personagens permite sintetizar os acontecimentos. Os fatos, suas motivações e consequências podem ser resumidos, de modo simplificado, nas qualidades e ações atribuídas a um personagem exemplar" (LEMOS, 2002, p. 113). Tomemos como exemplo o atleta Matt Stutzman (Figura 4) da modalidade de tiro com arco da equipe norte-americana. Nos últimos tempos, vídeos do atleta realizando performances esportivas têm sido veiculados nas redes sociais. Sua página no Facebook ,"The Armless Archer", possui 28.592 curtidas $^{16}$, há vídeos em sua página em uma rede social com mais de três milhões de visualizações, o que lhe proporciona um destaque internacional. Podemos considerar o atleta como representante de um determinado grupo estigmatizado que pode receber atribuições sociais das quais os integrantes 
desse grupo não venham a se sentir representados, ou podem se sentir incomodados da maneira como os identificam.

É possível dizer que o papel desempenhado socialmente pelos paratletas pode ser descrito como o de pessoas que ocupam o lugar de representantes do seu grupo (de pessoas com diagnóstico de deficiência). Esses sujeitos amenizam o peso de ser uma pessoa com deficiência. Afinal, mostram constantemente por meio do paradesporto, o que são capazes de fazer, o que proporciona certo consolo àqueles que de algum modo são sempre vistos pelas suas "incapacidades" (GONÇALVES; ALBINO; VAZ, 2009, p. 164).

No videoclipe em análise a demonstração de capacidade e o consolo às pessoas com deficiência aparece, por exemplo, no momento anterior a entrada da imagem do atleta realizando o tiro com o arco, quando a letra da música expressa a seguinte frase: "Tenho o pressentimento que posso fazer qualquer coisa, sim, eu posso". Tal expressão, de certa maneira, proporciona olhar para a performance do atleta como uma forma de superação. Conforme Goffman (2015), faz parte também do papel do representante discursar sobre a possibilidade da realização de feitos que, até então, eram considerados impossíveis. Consolida-se assim, a existência de uma identidade social real criada entre o seu grupo e outros que se sentem representados.

Em contraponto ao argumento de representantes que podem inspirar, ainda na perspectiva de estigma para Goffman (2015), o autor disserta que sobre os representantes "são publicados, como exemplo, histórias de fundo moral sob a forma de biografias ou autobiografias que ilustram um código desejável de conduta para os estigmatizados" (GOFFMAN, 2015, p. 34). Nesse sentido, a representação das pessoas e atletas com deficiência pela narrativa dos super-humanos pode promover a estigmatização deste grupo social, culpabilizando aqueles que não seguirem o referido código, pois:

cada vez que alguma pessoa que tem um estigma particular alcança notoriedade, seja por infringir a lei, ganhar um prêmio ou ser o primeiro em sua categoria [...] todos os que compartilham o estigma da pessoa em questão tornam-se subitamente acessíveis para os normais que estão imediatamente próximos e tornam-se sujeitos a uma ligeira transferência de crédito ou descrédito. Dessa maneira, sua situação leva-os facilmente a viver num mundo de heróis e vilões da sua própria espécie, sendo a sua relação com esse mundo sublinhada por pessoas próximas, normais ou não, que lhes trazem notícias do desempenho de indivíduos de sua categoria (GOFFMAN, 2015, p. 37).

Alinhado aos escritos de Goffman, no momento em que a narrativa audiovisual produzida pelo Channel 4 e chancelada pelo IPC adota uma posição de representar os atletas e, por consequência, as pessoas com deficiência como possíveis super-humanos, ela os coloca em uma linha de tensões entre o crédito e o descrédito, entre o heroísmo e a vilania de corresponder ou não a tais expectativas que estigmatizam todo o grupo social por intermédio dos seus representantes ali apresentados. 


\section{As representações empíricas das pessoas com deficiência no videoclipe}

Na narrativa construída a partir do videoclipe, identificamos ao menos três elementos que podem ser elencados como mecanismos de construção dos atletas e pessoas com deficiência como representantes do coletivo social, não se restringindo ao referido grupo e, inclusive, fazendo projeções para o futuro. O primeiro mecanismo é o do discurso nacionalista e da imagem de nação que se une em torno de um objetivo comum. $\mathrm{O}$ segundo mecanismo de representação é o uso de atletas com deficiência para explicarem o código, a regra ou a característica de determinada modalidade paralímpica. O terceiro mecanismo identificado foi a construção de uma representação de futuro por meio da imagem de crianças com deficiência que correm e brincam com suas próteses, como também a apresentação de atletas com deficiência praticando algumas modalidades que estão começando a ocupar um novo espaço na cultura esportiva global, como Escalada, MMA (artes marciais mistas - na tradução para o português) e Karatê.

\section{A representação no discurso nacionalista}

No caso dos frames destacados abaixo (figuras 5, 6 e 7), o Channel 4 apresenta atletas representantes do ParalympicsGB, modo como se denomina a delegação britânica que representa aquele conjunto de países nos Jogos Paralímpicos. A produção do videoclipe utiliza imagens de uma gama variada de modalidades paralímpicas, com diferentes atletas homens e mulheres em competição, se esforçando e vestindo as cores da bandeira britânica. É uma forma de eleger os atletas com deficiência como representantes da nação e assim desenvolver o sentimento de pertencimento e identidade do público consumidor com os referidos atletas. Dessa forma, procura-se criar a sensação de unidade em torno da diferença e colocar os atletas com deficiência daqueles países na mesma condição que outros, como por exemplo os atletas do futebol e os atletas olímpicos.

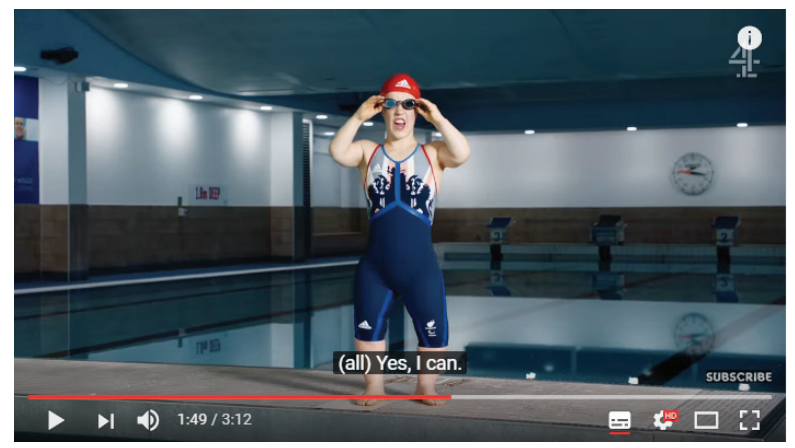

Figura 5

Fonte: Videoclipe "We're the Superhumans" 


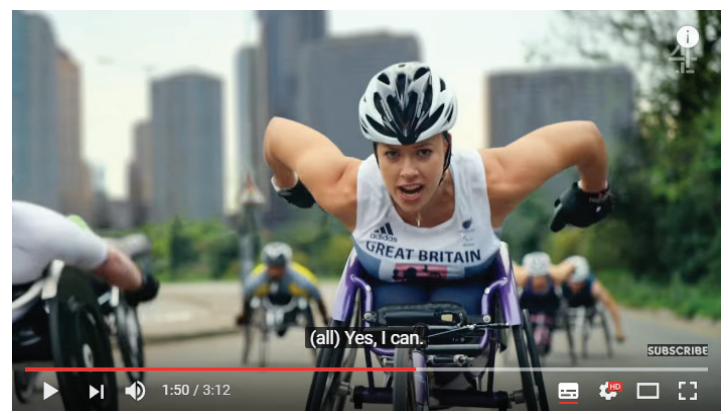

Figura 6

Fonte: Videoclipe "We're the Superhumans"

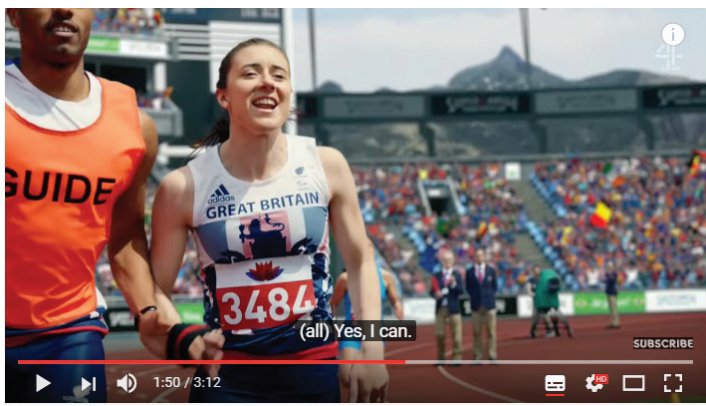

Figura 7

Fonte: Videoclipe "We're the Superhumans"

Ao reconhecermos que as pessoas e atletas com deficiência podem ser um grupo estigmatizado por uma identidade social virtual (GOFFMAN, 2015), o esforço do videoclipe se configura em reestabelecer a identidade dos mesmos por meio do sentimento nacionalista. Como afirma Bitencourt (2009, p. 177), “a identidade é um conceito escorregadio e está mais vinculado ao ser em contexto do que ao ser absoluto. Só há identidade na relação. É preciso um outro para que se possa estabelecer a identidade. Só há identidade na alteridade". Desse modo, em uma construção de contexto que explora as expressões dos atletas como força, garra, competitividade, assim como a indumentária deles - vestidos em uniformes com as cores da bandeira nacional britânica - o Channel 4 procura criar uma identidade de povo e nação não necessariamente existente. A narrativa do videoclipe remete a pessoa e o atleta com deficiência a uma condição de cidadão e representante britânico, assim como busca trazer o cidadão britânico comum à condição de se reconhecer representado pelas pessoas e atletas com deficiência. Esse é o modo pelo qual a criação de uma identidade normalmente se ampara, em um sistema de práticas e símbolos operados em contextos específicos (BITENCOURT, 2009).

A narrativa nacionalista que estava sendo promovida no videoclipe também foi utilizada como mecanismo de representação para o Brasil como país que sediaria a edição 
dos Jogos Paralímpicos 2016. Ao apresentar o músico brasileiro, Johnatha Bastos ${ }^{17}$, que tem uma má formação congênita nos braços, tocando teclado com a parte atrofiada dos braços e ao fim do vídeo escovando os dentes em um banheiro, vestindo uma camisa com a bandeira do Brasil estampada no peito (conforme a figura 8), o Channel 4 procura ativar também a brasilidade e relacioná-la ao grupo de pessoas com deficiência. Como uma das maiores produtoras e promotoras dos Jogos Paralímpicos no mundo por ser uma das principais redes de televisão detentoras dos direitos de transmissão, a Channel 4 primeiro mobilizou símbolos do seu público local, britânico, e mais ao fim acionou símbolos de contexto do público brasileiro, consumidor potencial do megaevento já que o mesmo se realizaria no Brasil, como uma forma de convite para esse público assistir aos Jogos no Brasil.

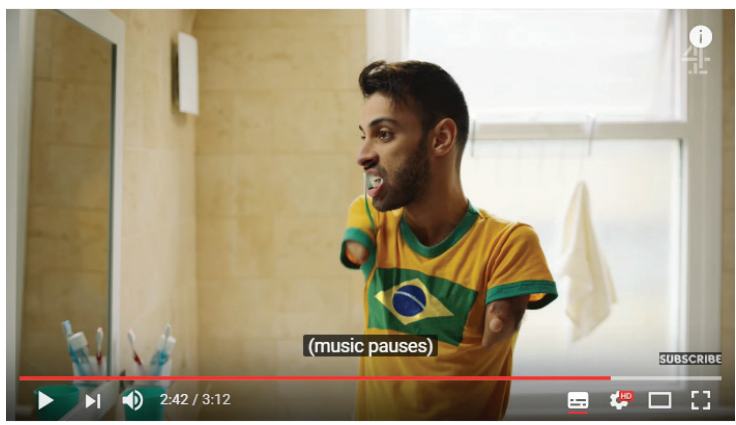

Figura 8

Fonte: Videoclipe "We're the Superhumans"

Diante de uma certa dificuldade existente em definir símbolos socioculturais que representam nacionalmente um país permeado por diversidades culturais e desigualdades sociais, a utilização da bandeira nacional associada a um artista com deficiência do país acabou se tornando uma estratégia de vinculação e atração do público brasileiro no despertar de um sentimento de representação no espetáculo paralímpico. Aqui consideramos também a grande divulgação e circulação que o videoclipe teve no contexto brasileiro, sendo publicado inclusive na página oficial do Comitê Paralímpico Brasileiro no facebook no dia 2 de agosto de 2016 já com legendas em português, tendo mais de 67 mil visualizações e mais de 2800 compartilhamentos. Conforme argumenta Bitencourt (2009, p. 178-179),

A identidade manifesta-se por meio de práticas e símbolos, pois sua configuração é fluida. É preciso que algo represente essa coletividade imaginada na qual nos organizamos. Em diferentes aspectos o esporte tem cumprido esse papel. A consolidação dos Estados nacionais, a confirmação de uma marca no mercado econômico, a invenção da face visível de uma escola ou universidade têm tomado apoio no efeito social do esporte.

17 Em destaque no videoclipe em 1:06, 2:12 e 2:42. Em outro vídeo, o músico comenta sobre sua participação no clipe: https://www.youtube.com/watch? $v=y$ Vr9zrwRc08. 
Não foi diferente com a narrativa construída pelo videoclipe do Channel 4 ao buscar um símbolo (as cores e a bandeira nacional) como forma de representação das pessoas com deficiência junto ao Brasil e aos brasileiros, mobilizando o efeito social do esporte, neste caso voltado ao universo dos Jogos Paralímpicos. Apesar de serem megaeventos esportivos assim como a Copa do Mundo de futebol masculino, os Jogos Paralímpicos e os Olímpicos não possuem o mesmo potencial de significado e de mobilização nacional no Brasil como o campeonato de futebol (BITENCOURT, 2009). Desse modo, em um esforço de colocar o fenômeno do esporte paralímpico na pauta do público brasileiro, a narrativa elegeu um representante com deficiência, neste caso não necessariamente um esportista, para criar "uma identificação duradoura entre o povo e esses esportes" (BITENCOURT, 2009, p. 185).

\section{A representação na mediação informativa das modalidades paralímpicas}

Outro mecanismo de representação que identificamos na narrativa audiovisual do videoclipe foi o uso de atletas com deficiência para apresentarem características de determinadas modalidades paralímpicas, como o exemplo do futebol de 5 (para cegos). Nas figuras 9 e 10, destacamos um frame do videoclipe em que um atleta da modalidade aparece fazendo o gesto e o sinal sonoro de pedido de silêncio (Shiii!) antes de surgirem as cenas subsequentes de uma partida da modalidade, a qual necessita do silêncio da torcida durante a disputa para que os atletas possam guiar os seus movimentos dentro de quadra a partir do guizo existente na bola e das orientações dos auxiliares, que ficam atrás dos gols gritando e emitindo sons com batidas nos ferros das traves.

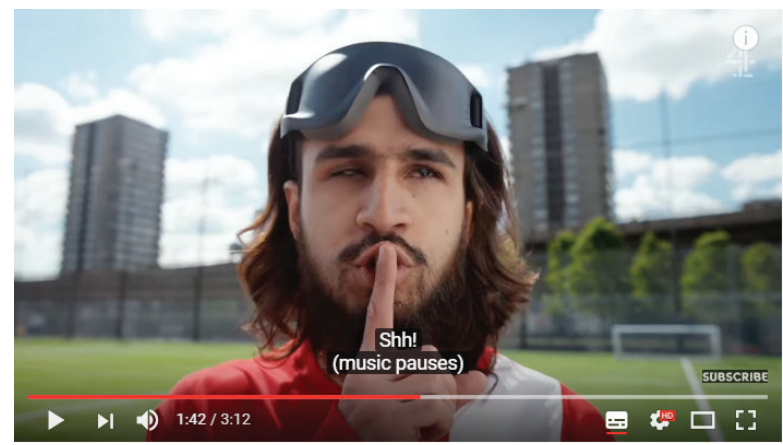

Figura 9

Fonte: Videoclipe "We're the Superhumans" 


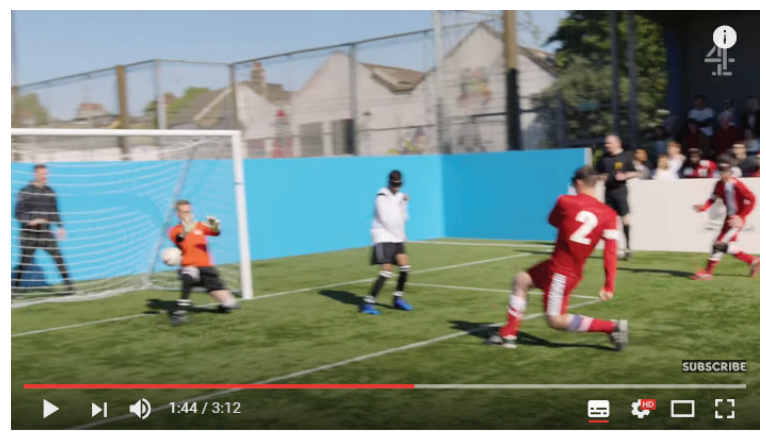

Figura 10

Fonte: Videoclipe "We 're the Superhumans"

Visto que o esporte paralímpico e as modalidades disputadas neste contexto são ainda pouco conhecidas pelo público, pois estão em decorrente processo de midiatização e consequente massificação (MARQUES; GUTIERREZ, 2015), as regras, normas e formas de disputa por vezes podem confundir e até afastar os espectadores que poderiam ser atraídos à prática e ao consumo desta manifestação esportiva. Nesse sentido, destinar um tempo e espaço do videoclipe à explicação da necessidade do silêncio durante as competições de futebol de 5 é um mecanismo de utilização dos atletas com deficiência para representar a cultura esportiva paralímpica, sobretudo ao produzir o frame inicial da seção com o plano fechado no rosto do deficiente visual. Este mecanismo mobilizado na produção do videoclipe caracteriza a operacionalização daquilo que Pires (2002, p. 42) definiu como cultura esportiva,

O conjunto de ações, valores e compreensões que representam o modo predominante de ser/estar na sociedade globalizada, em relação ao seu âmbito esportivo, cujos significados são simbolicamente incorporados através, principalmente, da mediação feita pela indústria da comunicação de massa.

Ou seja, além dos valores, compreensões e modos de agir referentes às pessoas com deficiência e aos atletas paralímpicos mobilizados pelo videoclipe e que já ressaltamos aqui (o sentimento nacionalista e a supervalorização das capacidades e habilidades deles) a produção audiovisual também os utiliza como representantes e protagonistas da mediação feita pela mídia sobre os modos de se compreender as modalidades e assim ampliar o repertório cultural do público acerca do esporte paralímpico. Esta talvez seja uma forma de compreender que o público consumidor vai se tornando fiel ao produto a partir do momento que também consegue entender a sua forma de disputa de modo racional, não só por meio de elementos emocionais como o nacionalismo e a superação. 


\section{Representação na projeção de futuro: A imagem da criança e as novas modalidades}

Outro elemento utilizado na narrativa do videoclipe como forma de representação por intermédio das pessoas com deficiência é a projeção de futuro. Aqui abordaremos as novas modalidades esportivas que ganharam visibilidade nos últimos anos, como também a participação de crianças com deficiência na peça publicitária analisada. Lisbôa (2014, p. 8), baseada em outros autores (Sampaio, 2000, e Buckingham, 2012), chama a atenção para três aspectos importantes que permeiam a participação infantil nas propagandas e publicidades dos meios de comunicação, são eles: "1) Potencial - [...] necessários como clientes do futuro; 2) Operante - capaz de mobilizar e agir conforme seus desejos de consumo no presente $[. .$.$] ; 3) Catalizadora - atingindo ou influenciando o consumo de$ terceiros, especialmente os adultos/pais".

Ao apresentar pessoas com deficiência desenvolvendo práticas corporais como Escalada (figura 11), Karatê (figura 12) e MMA (figura 13), a produção audiovisual posiciona esse grupo social como presente também em um âmbito esportivo atual e que tem ganhado maior visibilidade midiática nos últimos anos. Essa narrativa os projeta para um futuro de ampliação, de desenvolvimento e participação nas diferentes possibilidades do universo esportivo. As duas primeiras (Escalada e Karatê) são modalidades que irão compor o quadro olímpico de disputa na edição de Tóquio, em 2020. O MMA é uma das modalidades esportivas mais assistidas mundialmente devido à popularização do UFC (Ultimate Fighting Championship), que é um grande espetáculo midiático de Artes Marciais Mistas. Assim, o videoclipe tenta ampliar o espectro com que se olha o universo das pessoas e atletas com deficiência, indicando-o como ilimitado e com representantes nos mais variados âmbitos da cultura esportiva global.

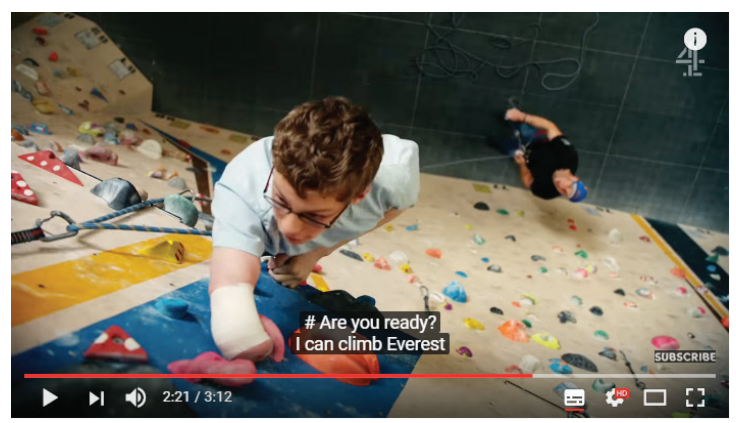

Figura 11

Fonte: Videoclipe "We 're the Superhumans" 


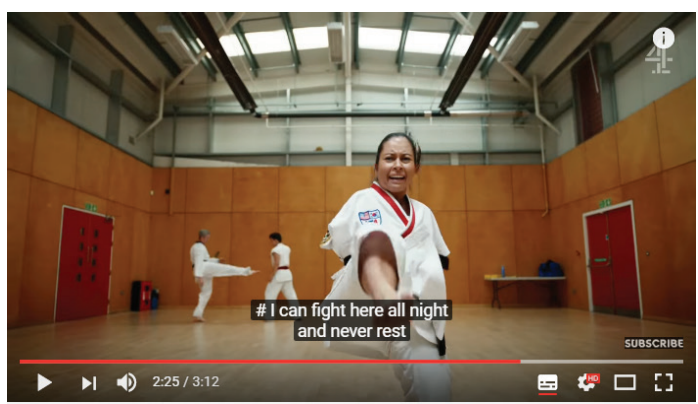

Figura 12

Fonte: Videoclipe "We're the Superhumans"

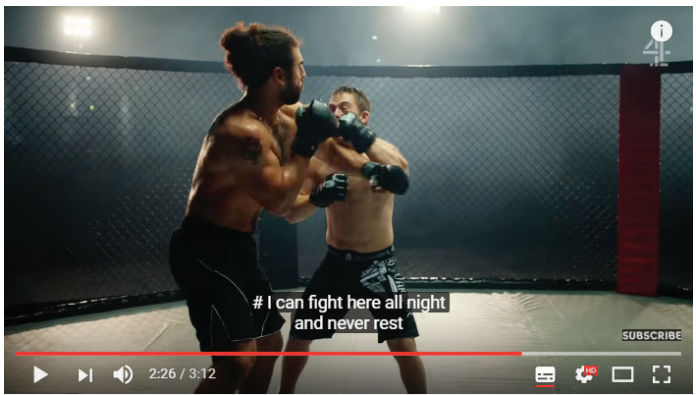

Figura 13

Fonte: Videoclipe "We're the Superhumans"

No outro mecanismo de projeção para o futuro, o Channel 4 desliza o sentido de possíveis representantes para o universo infantil (conforme figuras 14 a 17), apresentando crianças com deficiências, usuárias de braços ou pernas mecânicas, que brincam, chutam uma bola, pulam, estudam e participam em uma sala de aula. Ao caracterizar esse contexto da infância de forma alegre, com as crianças com deficiência aparecendo sorridentes, o videoclipe procura projetar um futuro no qual a sociedade, de forma geral, e as próprias pessoas com deficiência acreditem que elas são capazes e que, mesmo com algum tipo de deficiência, podem viver uma vida feliz como qualquer cidadão. 


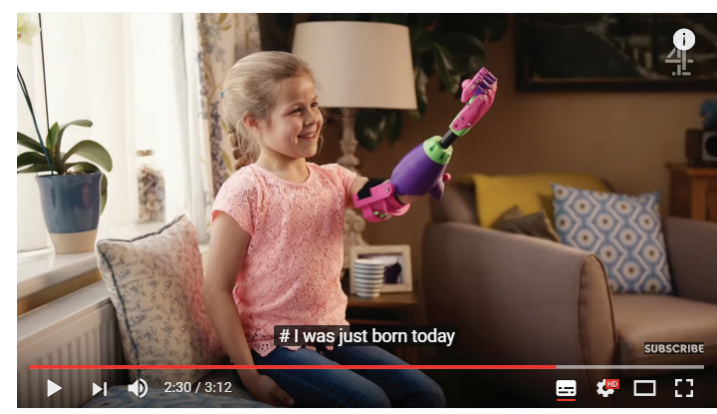

Figura 14

Fonte: Videoclipe "We' re the Superhumans"

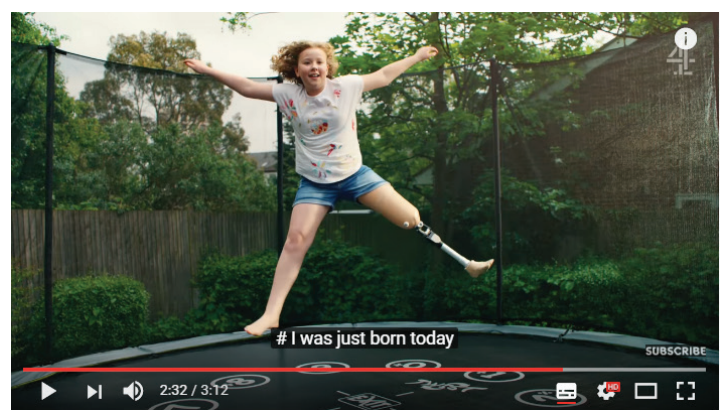

Figura 15

Fonte: Videoclipe "We 're the Superhumans"

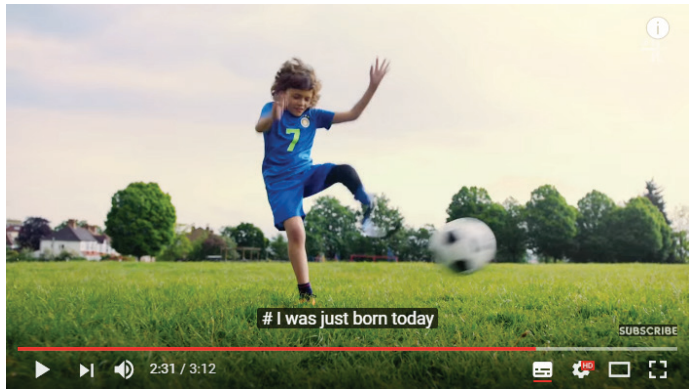

Figura 16

Fonte: Videoclipe "We 're the Superhumans" 


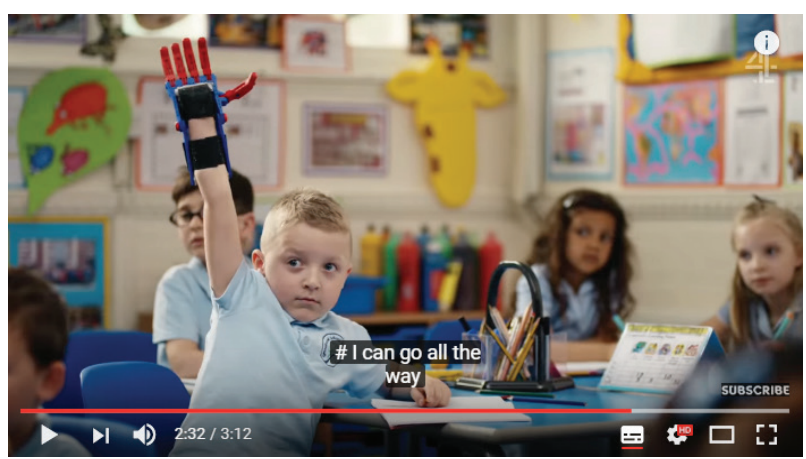

Figura 17

Fonte: Videoclipe "We're the Superhuma

Essas duas formas de mobilizar uma projeção ao futuro na construção narrativa de formas de representação dos atletas e das pessoas com deficiência através da peça publicitária sugere uma ambiguidade a ser problematizada. Por um lado, apresentar imagens de crianças nesse contexto e também a manifestação do esporte para pessoas com deficiência em novas modalidades esportivas pode indicar uma perspectiva de sociedade inclusiva, em específico através do fenômeno esportivo e do movimento paralímpico. Por outro lado, tanto a novidade das modalidades, como a presença das crianças, pode ser uma materialização/reprodução do modelo operacional da indústria cultural, conforme previsto por Horkheimer e Adorno (1985), no qual para todos os públicos está previsto algo a ser produzido e consumido. Ou seja, este discurso adotado pelo Channel 4 e pelo IPC no videoclipe pode ser um grande catalisador da inclusão social das pessoas com deficiência através do esporte, estimulando os consumidores desta produção a buscar e participar de uma prática esportiva. Neste caso, com a observação e a ressalva de não reproduzir o discurso evangelizador e salvacionista do esporte (SOUZA; MARCHI JÚNIOR, 2010) como eldorado social dos estigmatizados, discriminados e marginalizados. Porém, considerando o contexto de produção e o objetivo da peça publicitária, de promoção de um megaevento esportivo como os Jogos Paralímpicos do Rio 2016, que assim como todos os outros mobiliza grandes cifras econômicas (SOUZA; PAPPOUS, 2013), podemos considerá-la também como uma potente captadora de novos consumidores para o esporte paralímpico e as marcas publicitárias que o acompanham. O risco que se corre dessa maneira, é que ao invés de promoção e estímulo para inclusão social através da prática esportiva se esteja potencializando a substituição da experiência formativa e inclusiva do esporte por tempo de consumo mediado pelos meios de comunicação de massa, assim como previsto com a espetacularização do esporte (PIRES, 2002; COAKLEY, 2009).

O esporte associado aos meios de comunicação possui esse amplo poder de divulgação de atletas e de discursos, o que possibilita uma aproximação com aqueles que se interessam pelas práticas esportivas. Nesse sentido, cabe destacar que os meios de comunicação podem promover a representação da imagem dos atletas com deficiência 
de maneira estigmatizada, como também podem contribuir para o processo de inclusão (PAPPOUS et al, 2009). A mídia como um dos principais meios de disseminação de ideias, normas, valores, possui um papel importante no processo de uma construção social do corpo e da inclusão social das pessoas estigmatizadas que venham a se enquadrar ou não no discurso do "Yes, I can".

\section{CONSIDERAÇÕES}

A representação dos atletas com deficiência tem sido discutida por diferentes autores que buscam compreender a maneira como estes são apresentados e representados pelos meios de comunicação. Tais discursos são constituídos por normas e valores que permeiam a sociedade e influenciam diretamente a construção da imagem das pessoas com deficiência por parte da população que tem acesso a esse tipo de informação e conteúdo.

Neste trabalho, buscamos caracterizar a forma como os atletas paralímpicos foram representados no videoclipe "We're the Superhumans" produzido pelo Channel 4, trazendo alguns apontamentos referentes à produção do videoclipe que nos auxiliaram na discussão do supercrip e na construção de seus representantes. As retratações dos atletas sobre a categoria de supercrip, nos proporcionou a reflexão de que os atletas não foram representados a partir da sua deficiência, mas sim sob a ótica da performance esportiva ou em outras atividades como por exemplo, a dança, a música, tarefas do cotidiano e do trabalho. Como mencionamos, tal perspectiva possibilita a reflexão sobre a identidade social das pessoas com deficiência não negando quem elas são, tampouco vitimizando os sujeitos que ali aparecem.

Cabe ressaltar que o videoclipe contribui para um olhar ainda limitado sobre o esporte para pessoas com deficiência, pois pouco proporciona a discussão sobre as reais dificuldades sociais, estruturais e econômicas enfrentadas por essas pessoas cotidianamente em seu meio social. A exemplo, o único momento que aparece uma situação com conotação segregadora e preconceituosa, é no trecho em que o recrutador afirma para o cadeirante que ele não é capaz de realizar algo, com a expressão "No, You Can't".

Em relação a categoria de representantes, consideramos que os atletas paralímpicos apresentados neste videoclipe cumprem esta função por serem pertencentes a determinado grupo de pessoas historicamente estigmatizadas, por seus atributos serem diferentes da maioria. Constatamos também a produção de três elementos que trazem à tona a construção do(s) representante(s): 1 - Discurso nacionalista; 2 - Mediação informativa sobre as modalidades paralímpicas; 3 - A projeção do futuro a partir da imagem da criança e das novas modalidades. Tais elementos são essenciais para que o discurso de pertencimento seja receptivo ao público, entendendo que a produção do discurso não está apenas nas falas durante o vídeo, mas sim em toda a composição audiovisual desta produção. 


\section{REFERÊNCIAS}

BITENCOURT, Fernando Gonçalves. Esboço sobre algumas implicações do futebol e da copa do mundo para o Brasil: identidade e ritos de autoridade. Revista Brasileira de Ciências do Esporte, Campinas, v. 30, n. 3, p. 173-189, 2009.

BUYSSE, Jo Ann M.; BORCHERDING, Bria. Framing Gender and Disability: A Cross-Cultural Analysis of Photographs From the 2008 Paralympic Games. International Journal of Sport Communication, v. 3, n. 3, p. 308-321, 2010.

COAKLEY, Jay. Sports in Society: Issues and Controversies. 11. Ed. New York: Mc Graw Hill Education, 2009.

DEBORD, Guy. A Sociedade do Espetáculo. Rio de Janeiro: Contraponto, 1997.

DE LÉSÉLEUC, Eric; PAPPOUS, Athanasios Sakis; MARCELLINI, Anne. La cobertura mediática de las mujeres deportistas con discapacidad: Análisis de la prensa diaria de cuatro países europeos durante los Juegos Paralímpicos de Sidney 2000. Apunts, Educación Física y Deportes, v. 97, n. 3, p. 80-88, 2009.

DE LÉSÉLEUC, Eric; PAPPOUS, Athanasios Sakis; MARCELLINI, Anne. The media coverage of female athletes with disability: Analysis of the daily press of four European counties during the 2000 Sidney Paralympic Games. European Journal for Sport and Society, v. 7, n. 3-4, p. 283-296, 2010.

GOFFMAN, Erving. Estigma: notas sobre a manipulação da identidade deteriorada. 4 Ed. LTC. Rio de Janeiro, 2015.

GONÇALVES, Gisele Carreirão; ALBINO, Beatriz Staimbach; VAZ, Alexandre F. O herói esportivo deficiente: aspectos do discurso em mídia impressa sobre o ParapanAmericano/2007. In: PIRES, Giovani L. Observando o Pan Rio/2007 na mídia. Tribo da Ilha, Florianópolis, 2009.

HARDIN, Marie; HARDIN, Brent. The "Superscrip" in sport media: Wheelchair athletes discuss hegemony's disabled hero. SOSOL: Sociology of Sport Online, v. 7, n. 1, p. 1, 2004.

HILGEMBERG, Tatiane Hilgemberg. Do Coitadinho ao Super-heroi Representação social dos atletas paraolímpicos na mídia brasileira e portuguesa. Ciberlegenda, n. 30, p. 48-58, 2014.

HORKHEIMER, Max; ADORNO, Theodor. W. Dialética do esclarecimento. Rio de Janeiro: Zahar, 1985.

INTERNACIONAL PARALYMPIC COMMITTE. IPC Strategic Plan 2015-2018. Disponível em: https://www.paralympic.org/sites/default/files/document/150619133600866_201 5_06 + IPC + Strategic + Plan + 2015-2018_Digital.pdf. Acesso em: 23/08/2016

LEMOS, Cláudia Regina Fonseca. Visibilidade mediada: Personalização e promoções na cobertura de futebol. Revista Kinesis, Santa Maria, n. 26, p. 102-166, maio de 2002.

LIMA, Solange Ferraz.; CARVALHO, Vânia Carneiro. Fotografias. Usos sociais e historiográficos. In: PINSKY, Carla Bassanezi. et al. O historiador e suas fontes. São Paulo: Contexto, p. 29-60, 2009. 
LISBÔA, Mariana Mendonça. \#Joga pra mim? Publicidade e Infância na Copa do Mundo de Futebol. In: VII Congresso Sulbrasileiro de Ciências do Esporte, 2014, Matinhos/ PR. Anais... Matinhos/PR: Secretaria Estadual do Paraná/CBCE, 2014. p. 1-16. Disponível em: http://www.labomidia.ufsc.br/index.php/acesso-aberto/publicacoes/ publicacoes-2014/doc download/622-joga-pra-mim. Acesso em: 14/03/2017.

MARQUES, Renato Francisco Rodrigues; GUTIERREZ, Gustavo Luis. O Esporte Paralímpico no Brasil: profissionalismo, administração e classificação de atletas. São Paulo: Phorte Editora, 2015.

MEDRADO, Andrea Meyer. Culturas de Produção Digital nas TVs Públicas do Reino Unido. Revista Brasileira de Políticas de Comunicação, v. 6, p. 39-75, 2015. Disponível em: http://www.rbpc.lapcom.unb.br/index.php/revista/article/view/81. Acessado em 10/02/2017.

ORLANDI, Eni Puccinelli. Análise do discurso - princípios e procedimentos. Campinas, Pontes, 1999. 100p.

PAPPOUS, Athanasios Sakis et al. La visibilidad de la deportista paralímpica en la prensa escrita española. Revista de Ciencias del Ejercicio, v. 3, n. 2, p. 12-32, 2007.

PAPPOUS, Athanasios Sakis et al. La representación mediática del deporte adaptado a la discapacidad en los medios de comunicación. Ágora para la EF y el Deporte, n. 9, p. 31-42, 2009.

PAPPOUS, Athanasios Sakis; MARCELLINI, Anne; DE LÉSÉLEUC, Eric. From Sydney to Beijing: the evolution of the photographic coverage of Paralympic Games in five European countries. Sport in Society, v. 14, n. 3, p. 345-354, 2011.

PIRES, Giovani de Lorenzi. Educação física e o discurso midiático: abordagem críticoemancipatória. Ijuí: Unijuí, 2002.

PURDUE, David; HOWE, David. See the sport, not the disability: exploring the Paralympic paradox. Qualitative Research in Sport, Exercise and Health, v. 4, n. 2, p. 189-205, 2012.

SILVA, Carla Filomena; HOWE, David. The (In)validity of Supercrip Representation of Paralympian Athletes. Journal of Sport \& Social Issues, v. 36, n. 2, p. 174-194, 2012.

SOUZA, Juliano de; MARCHI JUNIOR, Wanderley. Os "legados" dos megaeventos esportivos no Brasil: algumas notas e reflexões. Motrivivência, Florianópolis, ano XXII, n. 34, p. 245-255, jun. 2010.

SOUZA, Doralice Lange de; PAPPOUS, Athanasios Sakis. Legados esportivos de megaeventos esportivos: uma revisão da literatura. Motrivivência, Florianópolis, ano XXV, n. 41, p. 42-56, 2013.

TYNEDAL, Jeremy; WOLBRING, Gregor. Paralympisc and its athletes through the lens of the New York Times. Sports, v. 1, n. 1, p. 13-36, 2013. 